\title{
Secondary Aneurysmal Bone Cyst Located in the Acetabulum: A Case Report
}

\section{Asetabulum Yerleşimli Sekonder Anevrizmal Kemik Kisti: Olgu Sunumu}

\author{
Reşit Sevimli' ${ }^{1}$ Yavuz Yener Sağlık², Yusuf Yıldız ${ }^{2}$ \\ ${ }^{1}$ İnönü Üniversitesi Tıp Fakültesi, Ortopedi Ve Travmatoloji Ana Bilim Dalı, Malatya, Türkiye \\ ${ }^{2}$ Ankara Üniversitesi Tıp Fakültesi, Ortopedi Ve Travmatoloji Ana Bilim Dalı, Ankara, Türkiye
}

Doi: $10.5505 /$ aot.2012.66375

\section{ÖZET}

Anevrizmal kemik kisti, primer kemiğin selim tümör benzeri lezyonlarından olup, nispeten az görülen bir benign kemik tümörüdür. Asetabulum yerleşimli olması genellikle nadirdir. Daha önceden var olan benign veya malign bir lezyon üstünde görüldüğü zaman sekonder anevrizmal kemik kisti olarak adlandırılır. Bu yazıda sol kalça çevresinde iki yıldır var olan ağrı nedeniyle başvuran sekiz yaşında erkek hastanın, küretaj ve kemik sement augmentasyonu ile tedavi edilen, asetabulum lokalize basit kemik kisti üzerinde gelişmiş sekonder anevrizmal kemik kisti olgusu sunulmuş ve literatür taraması yapılmıştır.

Anahtar Kelimeler: Asetabulum; Anevrizmal kemik kisti; Basit kemik kisti

\begin{abstract}
Aneurysmal bone cyst, benign tumor-like lesions of primary bone is a relatively rare benign bone tumor. The acetabulum located lesion is rare. It was called as secondary aneurysmal bone cyst when it is located on a Preexisting benign or malignant lesion. In this article, 8 years old patient who admitted with the pain around the left hip and treated with curettage and bone cement augmentation because of the acetabulum localized simple bone cyst was presented with the development of the secondary aneurysmal bone cyst and the literature search was performed.
\end{abstract}

Key words: Acetabular; Aneurysmal bone cyst; Simple bone cyst

\section{Giriş}

Anevrizmal kemik kistleri (AKK) benign, ekspansil, damarsal, lokal destrüktif nonneoplastik lezyonlardır. Tüm primer kemik tümorlerinin \%1'ini oluştururlar, \%2'si asetabulum, \%8-12'si ise pelvis kökenlidir (2). AKK'nın kesin etiyolojisi hala tartışmalıdır. AKK'lar primer kemik lezyonları şeklinde (olguların \%70'i) veya diğer kemik kökenli lezyonlar zemininde gelişmiş (olguların \%30'u) olabilirler. Pelvik AKK'lar genellikle büyük ve vaskülaritesi yüksek lezyonlardır (3). AKK'nın tek başına görüldüğü primer tipleri olduğu gibi basit kemik kisti, kondroblastom, dev hücreli tümör, osteoblastom gibi selim, osteosarkom, malign fibroz histiyositom gibi habis tümorler ile birlikte olduğu sekonder formları vardır. En sık çocuklar ve genç erişkinler etkilenir; olguların \%75'i ilk başvuruda 20 yaşından küçüktür.
AKK tedavisine karar verirken lezyonun anatomik lokalizasyonu, kistin boyutu, büyüme hızı, patolojik kırık riski ve lezyonun primer veya sekonder olması gibi faktörler dikkate alınmalıdır. Tedavi seçenekleri arasında tam rezeksiyon, küretaj, küretaj ve kemik greftleme, küretaj + kemik sement ve selektif arteryel embolizasyon (primer tedavi olarak veya preoperatif terapi) ve perkütan fibrozan ajan enjeksiyonu say1labilir. Küretaj ve "en bloc" eksizyon, erişilebilen lezyonlar için birincil tedavi seçeneği olmasının yanı sıra radyasyon, kriyoterapi, perkütan intralezyonel enjeksiyon ve embolizasyon daha zor erişilebilen ve rekürren lezyonlar için kullanılan tedavi yöntemlerindendir (4).

$\mathrm{Bu}$ çalışmada asetabulumda basit kemik kisti üzerinde sekonder olarak gelişen epifizi tehtid eden lokal agresif yerleşimli sekonder AKK'nın küretaj ve greftleme+ 
kemik sement sonrası sorunsuz bir şekilde tedavi edildiği olgu tartışıldı.

\section{Olgu sunumu}

Sekiz yaşında erkek hasta merkezimize iki yıldır sol kalça çevresinde başlayan ağrı şikayeti ile başvurdu. Daha önceleri doktora gittiklerinde büyüme ağrıları olarak değerlendirilip ağrı kesici kullandığını belirtti. Fizik muayenesi sol kalçada palpasyonla hassasiyet dışında kalça hareketlerinin de ağrılı olduğu ve uzun süre yük vermekle şikayetlerinin arttı̆ 1 saptand. Laboratuar bulgular1 normaldi. Pelvis grafisinde sol asetabulumda destruksiyon izlendi (Resim 1). Bilgisayarlı tomografi (BT) ve manyetik rezonans görüntüleme (MRG) kesitlerinde sol asetabulumda iskiyuma kadar uzanan multiseptalı $3 \times 5 \times 4 \quad \mathrm{~cm}$ boyutlarinda kitle izlendi (Resim 2,3). Pubik kemikte minimal ödem mevcuttu. Sol kalça eklemi minimal sıvı varlığı dışında normaldi. Radyolojik tanı asetabulumda AKK şeklindeydi. Genel anestezi altında hasta operasyona alınıp kist temizlendikten sonra boşluk kemik çimentosu ile dolduruldu (Resim 4,5). Operasyon sonras 1 kalça hareketlerinde ve 10 yıllık takiplerinde kalça epifizinde herhangi bir sorun yaşanmadı (Resim 6,7).
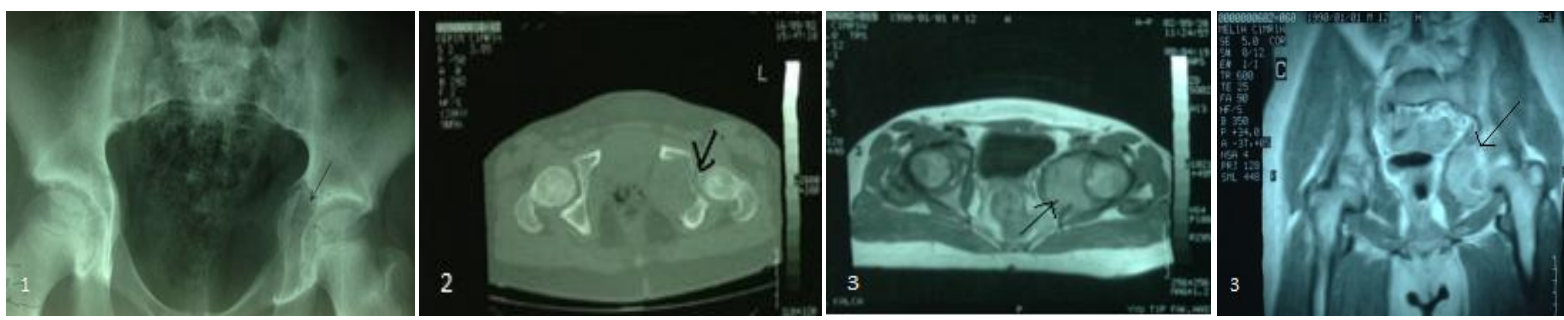

Resim 1:Hastanın preoperatif AP grafisi, 2: Preoperatif BT kesiti, 3: Preoperatif MRG kesitleri
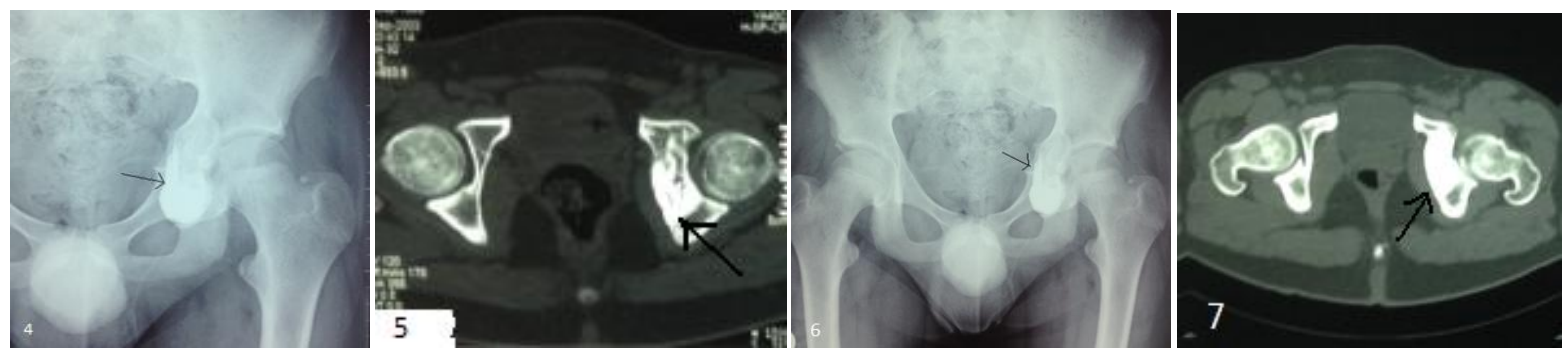

Resim 4: Küretaj ve çimentolama sonrası AP ve Lateral Grafisi, 5: Küretaj ve çimentolama sonrası BT kesiti, (eklem yüzünün düzgün olduğu görülmekte),6: Ameliyat sonrası 3. yıl AP grafisi, 7: Ameliyat sonrası 5. yıl BT kesiti

\section{Tartışma}

AKK içi kan veya kan hücrelerinden zengin bir sivı ve fibroz doku ile dolu, kist benzeri benign bir kemik lezyonudur (5). Primer kemik tümörleri içinde, diğerlerine göre nispeten az görülür. Pediatrik yaş gurubunda pelvis yerleşimli AKK çok nadirdir. Novais ve ark. 142 AKK teşhisi almış çocuk hastanın 18 tanesinde pelvis yerleşimli olduğunu bildirmiştir (6). Cottalorda ve ark.'nın 156 hastalık serisinde pelvik yerleşimli AKK hasta oranı yalnızca $\% 9$ olarak bildirilmiştir (7). Doframan ve Czerniak ise pelvik yerleşimli AKK hasta oranının \%2.5 ve erkek kadın oranının eşit olduğunu, olguların ikinci dekatta artış gösterdiklerini belirtmişlerdir (9). Olguların \% 85'i 20 yaşın altındadır. Uzun kemikler ve vertebra en s1k yerleşim bölgeleridir.

Ağr1 şikayetleri birkaç hafta ile birkaç y1l arasında değişmektedir. Her ne kadar Dorfman sekonder AKK oranını \%50 olarak belirttiyse de diğer yayınlara göre oran $1 / 3$ oranındadır (9). Tanıda direkt grafi, BT ve MR beraber değerlendirilir. Lezyonun görünümü hastalığın evresine göre değişebilmektedir. AKK'nin aktif olduğu ilk evrelerde ekspanse olan kemiğin sınırları belirgin olmadığı için malign bir lezyona benzetilebilir.

AKK'nın tipik radyografik görünümü, eksantrik yerleşimli, ekspansil, yer yer osteolitik kemik lezyonu şeklindedir. BT ve 
MRG'de ise lezyonda bal peteği görünümünde iç septalar ile birlikte sıvı-sıvı seviyeleri izlenir (3). Olgumuzun radyolojik incelemelerinde s1v1-s1v1 seviyelerine rastlanmad1. AKK normal kemikte gelişebildiği gibi, \%29-35 oranında, dev hücreli tümör, kondroblastom, kondromiksoid fibrom, osteosarkom, fibröz displazi, eozinofilik granülom, basit kemik kisti ve travma gibi daha önceden var olan lezyon zemininde de gelişebilir ve sekonder AKK olarak adlandırılır (4). AKK'nin kistik ve solid tiplerinin de ayırt edilmesi önemlidir. Literatürde bildirilen solid tip AKK olgularının hepsi, klasik AKK ile benzer özelliklere sahiptir; olgumuzda herhangi bir solid komponent mevcut değildi.

Pelvik AKK tedavisi, intraoperatif kanama riski, lezyonların nörovasküler yapılarla komşuluğu ve asetabulum veya sakroiliyak eklemin bütünlügünün hasar görmesi riskleri nedeniyle çoğunlukla güçtür. Tedavi seçenekleri tam rezeksiyon, küretaj ve kemik çimentosu, küretaj ve kemik greftleme ve perkutan fibrozan ajan enjeksiyonunu içerir (2). Asetabulum yerleşimli AKK'ların tedavisi, lezyonun yerleşimi, uzanımı ve agresifliği göz önüne alınarak dikkatli bir şekilde yapılmalıdır. Asetabulum yerleşimli AKK'-ların standart cerrahi tedavisi lezyonun lokal rezeksiyonu ve küretajı ile birlikte, oluşan boşluğun kemik grefti veya çimentosu (polimetilmetakrilat) ile kapatılmasıdır (10). Küretaj sonrası oluşan boşluğun kemik grefti ile doldurulmasıyla daha iyi sonuçlar alınabilmektedir.

Olgumuzun 5 yıllık takiplerinde nüks veya herhangi bir büyüme kusuru saptanmadi.
Asetabulum yerleşimli AKK iyi huylu olmasına karşın, yetersiz küretaj yapıldığında tekrarlama riskinin yüksek olduğu aşırı agresif davranıldığında da büyüme plağına zarar verilebileceği akılda tutulmalıdır.

\section{Çıkar Çatışması: Yok}

\section{Kaynaklar}

1. Campanacci M, Capanna R, Picci P. Unicameral and aneurysmal bone cysts. Clin Orthop Rel Res 1986;204:25-36

2. Cottalorda J, Bourelle S. Current treatments of primary aneurysmal bone cysts. J Pediatr Orthop B 2006; 15:155-67

3. Mirra JM. Aneurysmal bone cyst: clinical, radiologic, and pathologic correlations. 2nd ed. Philadelphia: Lea and Febiger, 1989;1267-311

4. Arlet V, Rigault P, Padovani JP, et al. Aneurysmal bone cysts in children: study of 28 cases. Rev Chir Orthop 1987;73:337-48

5. Beltran J, Simon DC, Levy M. Aneurysmal bone cysts: MR imaging at 1.5 T. Radiology 1986;158:689-90

6. Novais EN, Zimmerman AK, Lewallen LW, Rose PS, Sim FH, McIntosh AL. Functional outcomes and quality of life following surgical treatment of aneurysmal bone cystsof the pelvis in children. J Child Orthop J Child Orthop. 2014;8:281-8

7. Cottalorda J, Kohler R, Sales de Gauzy J, et al. Epidemiology of aneurysmal bone cysts in children: A multicenter study and literature review. J Pediatr Orthop B 2007;13:389-94

8. Mirra JM: Bone Tumors. Lea and Febiger. Philadelphia. 2: pp. 1989,1267-311

9. Dorfman HD, Czerniak B. Bone tumors. Mosby, New York 1998

10. Marcove RC, Sheth DS, Takemoto S, Healey JH. The treatment of aneurysmal bone cyst. Clin Orthop 1995;311:157-63 